allowed to pass between a brass ball as anode, and the cleaned surface of an amalgamated zinc disc as cathode, they disappear in the presence of magnesium light. And if the distance between ball and plate be enlarged, the magnesium light will also hinder the formation of positive electrical brushes.

[Cf. IViedemann's Annalen, Bd. 38, p. 40; 38, p. 497 ; 39 , p. 332 ; 4 I, p. I6I ; 41, p. 166; 42, p. $564 ; 43$, p. 225 ; 44 , p. $722 ; 46$, p. 281 ; 48, p. $625 ; 52$, P. 433 ; and Wiener Berichte, Bd. IOI, p. 703. March 1892.]

Wolfenbiittel, August 12.

\section{J. ELSTER.} H. Geitel.

\section{A Remarkable Meteor.}

Ox the evening of August 26 (Sunday) I saw what was to me an unprecedented sight : a brilliant and curious "meteor" fell near Gloucester. Starting from a point a little to the west of $\mathrm{K}$ "Diaco," at Ioh. I9m., falling in the direction shown in Fig. 1, through about an angle of $40^{\circ}$; when it reached point $x$,

POLE STAR.

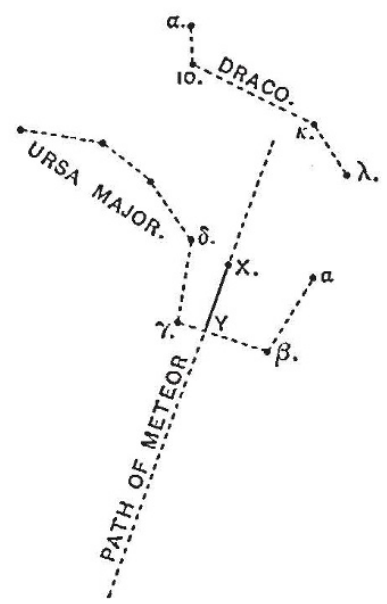

Fig. 1.

it appeared to melt, and its path from $X$ to $Y$ was marked by a most brilliant stream of light, equalling in intensity a magnesium flame.

This luminous streak from $\mathrm{X}$ to $\mathrm{Y}$ remained stationary and brilliant for nearly two minutes; then the lower extremity gradually curled around, forming the letter J, as shown in Fig. 2 ; the ends gradually converged until they met, forming a somewhat irregular band, and travelling in the path indicated by the arrow in Fig. 2.

As it traversed the heavens it seemed like a phosphores :ent or nebulous cloud, finally assuming the shape shown in Fig. 2;

POLE STAR.

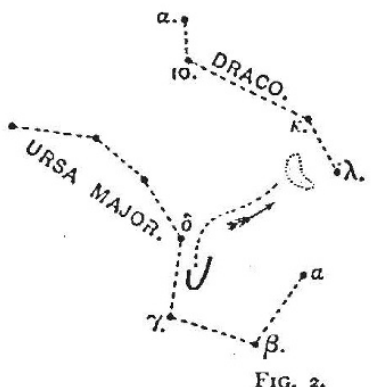

between $K$ and $\lambda$ "Draco," then gradually becoming fainter and fainter, until at roh. $4 \mathrm{Im}$. (just twenty-two minutes after the "meteor" fell) it became invisible, at a point as much to the eastward of $\mathrm{k}$ "Draco" as the "meteor" had started from the westward of it. I should like to know if any of your readers have seen a similar phenomenon, or if it is of common occurrence.

Gloucester, August 27. JOHN IV. EARLE.

\section{A New Rhynchobdellid.}

Ir seems hard to believe that a leech, common and abundant and possessing a chitinous dorsal scute, should have hitherto escaped notice. But Jackson, in his edition of the "Forms of Animal Life," does not refer to such a structure, nor does Lang, and I do not find notice of it in more recent literature. In the hope that I am not adding a needless synonym, I give a short description of the animal, of which a detailed account is in preparation.

(Glossiphonia?) scutifera, n. sp. Sub-cartilaginous, semi-transparent, greenish grey above, paler beneath ; obscurely striated above, with a row of dark spots on either side of the middle line. Body widest about 40 th annulus, tapering thence abruptly to the disc and gradually to the head, which is narrowest, and not marked off from the succeeding annuli. Annuli 64, ganglia 22. Length in full extension about I inch, at rest 3.8 ths of an inch. Eyes two in centre of head. Genital apertures behind 2 rst and 23 rd annuli. The 9 th annulus is broader than its neighbours, and carries on the hinder part of its richly glandular dorsum a chitinous plate slightly elongated transversely, covering about an eighth of the width of the annulus; in. young specimens the margins are overlapped by the integument. Anus dorsal.

This species is meanwhile referred to Glossiphonia, to which it bears a general resemblance.

Glasgow University, August 28.

The Bleaching of Beeswax.

CAN any of your correspondents inform me how to bleach beeswax chemically, satisfactorily, and at a moderate cost? August 28.

J. S. D.

\section{SUNSHINE AND WATER-MICROBES.}

THE bactericidal action of light is perhaps of most general hygienic significance in connection with the fate of micro-organisms in water, and there is ample field open for investigation in this direction, which so far has been but little explored. It is, therefore, with especial interest that we note Prof. Buchner's important contribution to this subject in the Arcliziv fiir Hygiene. The title of the paper ("Ueber den Einfluss des Lichtes auf Bacterien und uiber die Selbstreinigung der Flüsse") already indicates that the practical aspect of the question has been considered, and indeed several experiments have been planned and carried out with the object of ascertaining what is the part played by sunshine in the alleged bacterial purification which takes place in riverwater during its flow.

In the first series of experiments samples of boiled tapwater were inoculated with three drops of broth-cultures of the typhoid bacillus, $B$. coli communis and $B$. pyocyaneus respectively. The typhoid bacilli, even in diffused daylight, were reduced in numbers from 7400 perc.c. to start with, to 5000 at the end of one day, whilst on the second day none whatever were found. The $B$. coli communis sample had only 220 left on the third day, out of 22,600 at the commencement of the experiment, and was sterile on the fourth day; the $B$. pyocyaneus was, however, hardly affected at all during four days' exposure to diffused light.

The direct rays of the sun, however, were far more destructive. Thus about 30 c.c. of a sample of typhoidinfected water, placed in glass dishes and exposed to sunshine, contained no typhoid organisms at the end of six hours, and similar results were obtained with the $B$. pyocyaneus.

In all these experiments the perfectly admissible objection could be urged that the diminution in the numbers present might, at any rate in part, be attributed to a process of starvation in consequence of the absence of food-

No. I 297 , voL. 50] 
material, inasmuch as a marked decrease was also observed in those samples kept in the dark. To meet this objection, in the next series unsterile water was used, and to a litre and a half as much as I c.c. of the broth-culture of the particular organism was added, thus affording ample provision, both in light and darkness, for the support of the bacteria under observation. Instead of a decrease taking place in the samples kept in the dark, the numbers rose; on the other hand, in the samples placed in the sunshine, three hours' exposure in the case of the typhoid, colon, and pyocyaneus bacilli brought about their entire destruction, thus placing beyond doubt the direct bactericidal action which had taken place during insolation.

The amount of water used being small, no indication was.given, in these experiments, of the depth to which the bactericidal action of the sun's rays could extend. Fol and Saracen ("Sur la pénétration de la lumière du jour dans les eaux du lac de Genève," Comptes Rendus, 1884) have shown by the exposure of gelatine-bromide plates that daylight penetrates to a depth of 170 metres in the water of the Lake of Geneva, the degree of light at this depth being about equal to that which we find during a bright but moonless night, whilst at a depth of 120 metres the strength of light is still considerable. These investigators also made the curious observation that in the experiments they conducted, the light penetrated far deeper into the water in September, during cloudy weather, than in the month of August with a perfectly clear sky. Thus not only does the power of light vary at different depths and, doubtless, in different waters, but it is also influenced by the time of year; and what, therefore, may be correct of a given water under certain circumstances, may not necessarily apply to it on another occasion, and hence a good deal of uncertainty attaches to the exact degree of light capable of transmission in any particular mass of water.

Prof. Buchner has endeavoured to ascertain at what depth in the water of the Starnberger Lake, near Munich, light ceases to have any bactericidal action. For this purpose he used his well-known process (described in the Centralblatt fïr Bakteriologie, vol. xii. August 1892) of exposing partially protected agar-agar dish cultures. This ingenious method consists in covering over parts of a glass dish containing agar-agar, in which certain varieties of bacteria have been evenly distributed, with variously-shaped strips of black paper or lead, so that the light is screened from these particular portions of the surface. In this manner the bacteria immediately beneath the covered part of the culture-medium are protected from the antiseptic action of light, whilst the rest of the agar-agar and its contents is freely exposed; the result of which is that, in the shaded part of the dish the colonies make their appearance, but in the remainder, having been subjected to the action of light, no bacterial growths, or only very feeble ones, are visible. This is beautifully exhibited in a few days' time by the shape of the black letters or other figures being sharply delineated by the abundant growths which have taken place beneath them from the blank remainder of the dish where nothing is visible, no colonies having developed.

Recently infected agar-agar dishes, partially screened with a leaden cross, were lowered to particular depths in the Starnberger Lake. The day selected was very fine and sunny, and the exposure was continued for $4 \frac{1}{2}$ hours, the temperature of the water being $15^{\circ} \mathrm{R}$. The site was the starting-place of the steamers, and the water was not quite clear, this being doubtless due to the disturbance caused by the plying to and fro of the vessels.

It would have been more striking, perhaps, if Prof. Buchner had used only one variety of organism throughout, as then all chance of characteristic individual differences disturbing the progressive results would have been obliterated.

$$
\text { No. I } 297 \text {, vOL. 50] }
$$

The following table shows the results obtained :-

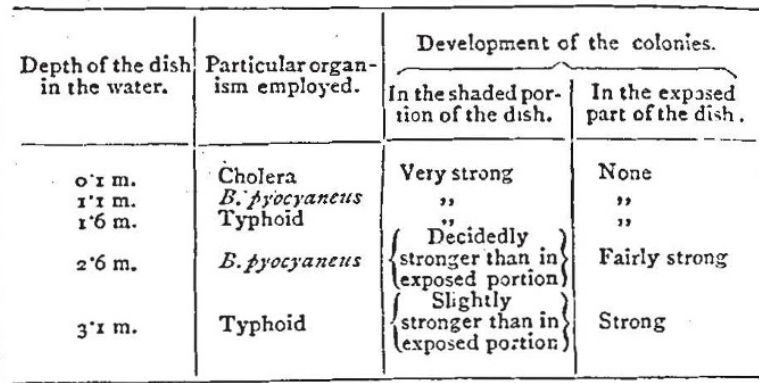

At a depth of $1.6 \mathrm{~m}$. the bactericidal action of the sun's rays, as shown by this method, is equal to that produced outside the water; but at $2.6 \mathrm{~m}$., however, the action is much less apparent, and in fact is only just.perceptible. Thus, as has been suggested elsewhere, ${ }^{1}$ the antiseptic potency of the sun's rays ceases a long time before the light becomes affected by the depth of water it has to traverse.

These experiments are of particular interest and im. portance, because they show very clearly that the agency of light in purifying water cannot be regarded as of much importance. So much stress has recently in Germany been laid upon the self-purification of river-water, that the advisability of permitting the sewage of cities of the magnitude of Cologne to pass untreated into the Rhine, has been publicly discussed on the assumption that in its subsequent flow all objectionable matters will disappear, one of the agencies cited as materially assisting in this magic destruction being sunlight. It is, however, sufficiently apparent that the action of light can only affect a very small fraction of the whole mass of water, for we know that bacteria exist in large numbers at depths very considerably below those which insolation can embrace, whilst there are only a few months in the year, at any rate in our northern climes, when the sun's action is sufficiently strong or prolonged to produce any appreciable effect even in the upper layers of the water.

Prof. Buchner concludes his paper with some investigations carried out by his assistants on the River Isar, Io $\mathrm{km}$. above Munich. These experiments were made to ascertain if any increase from the number of organisms present during the daytime takes place in the night, as in the absence of light might reasonably be anticipated. Dr. Minck and Dr. Neumayer, therefore, undertook on a September night to abstract samples from the river at $\frac{1}{4} \mathrm{~m}$. below the surface at intervals of from $\mathrm{I}-2$ hours from 6 o'clock in the evening until 6 o'clock the next morning. The temperature of the water during this time only varied between $9^{\circ}-10^{\circ} \mathrm{R}$., and the samples were examined immediately after collection. The results are recorded in the following table: -

\begin{tabular}{|c|c|}
\hline \multicolumn{2}{|c|}{ Time of taking sample. } \\
\hline $6 \frac{1}{4}$ & evening \\
\hline $8 \frac{3}{4}$ & 3 \\
\hline II & $"$ \\
\hline & morning \\
\hline 3 & " \\
\hline 4 & " \\
\hline $\begin{array}{l}5 \\
6 \frac{1}{4}\end{array}$ & " \\
\hline
\end{tabular}

Number of microbes in absut 20 drops of water.

It would be interesting to have further confirmation of the results here given, other factors having doubtless assisted besides the absence or presence of light; but the arduous nature of the experiments will doubtless greatly militate against such a series being sufficiently often made to permit of any definite conclusions being arrived

" "Bacterial Life and Light," Longman's . Wagazine, September, 1893. 2 No explanation is offered for these abnormally low figures. 
at. In this connection, it may also be noted that in the year 1886 the Thames water at Hampton contained twenty times as many microbes in the winter as were found in the summer months. Here again the cons1deration of other agencies also tending to influence the bacterial condition of the river water cannot be excluded, but sunshine undoubtedly assisted in the banishrnent of the microbes.

G. C. FRANKLAND.

\section{NOTES.}

THE MIunicipal Council of Paris has opened competitions for the best means of suppressing or diminishing the smoke of cities, and of purifying water. To the author of the best memoir on the former subject, the sum of ten thousand francs will be given, and two other prizes will be awarded of five thousand and two thousand francs respectively. The memoirs must be sent in before November 1. Prizes varying from one thousand to three thousand francs will be awarded for the processes of water purification which give the best results. Papers relating to this must reach the Council before September 15 .

THE death is announced of Dr. Karl Neumann, Professor of Chemistry in Zürich Polytechnic School, at the age of fortythree.

We learn from the Alhencum that Father Epping, S.J., died on August 22. He was one of the highest authorities on Assyrian astronomy and chronology, on which subject he published, in conjunction with Father Strassmaier, a valuable treatise some years ago.

THE tenth International Congress of Orientalists was opened at Geneva on Tuesday. Fourteen Governments, and ninetyseven Universities or learned societies, have sent delegates to the meeting.

THE International Congress of Hygiene and Demography is now being held at Budapest. We hope to give a report of the proceedings after the meeting has ended.

THE Association Géodésique Internationale met at Innsbruck yesterday. M. Faye, M. Bouquet de la Grye, and M. Tisserand were delegated by the Paris Academy of Sciences to attend the meeting.

THE International Meteorological Committee held its meeting, as arranged, at Upsala, August 20-24. M. Wild, the president, was unfortunately prevented from attending, owing to indisposition. M. Mascart was elected president for the meeting, and Mr. Scott, as usual, secretary; the other members present were Prof, v. Bezold (Berlin), Dr. Billwiller (Zürich), Mr. WV. G. Davis (Cordoba), Dr. Hann (Vienna), M. Hepites (Bucharest), Dr. Hildebrandsson (Upsala), Prof. Mlohn (Christi. ania), Dr. Paulsen (Copenhagen), M. Snellen (Utrecht), and Prof. Tacchini (Rome); the absentees were, in addition to the president, Admiral de Brito Capello (Lisbon), owing to health, and Messrs. Eliot (Simla), Ellery (Melbourne), and Harrington (Washington), owing to distance. The principal points dealt with at the meeting were as follows:-(I) The establishment of an International Meteorological Bureau was recognised as impracticable. (2) It was resolved to publish in the report of the meeting a resums of the measures adopted in all countries to communicate to agriculturists meteorological results likely to be useful to them. (3) The acceleration of meteorological telegrams. It was decided to address the International Telegraphic Bureau at Berne on this subject. (4) The scintillation of stars as an indication of weather. A paper by M. C. Dufour

$$
\text { NO. I } 297 \text {, VOL. 50] }
$$

will be reproduced in the report. (5) The study of clouds. This was the piece de resistance at the meeting. The Cloud Committee, appointed at Munich in $189 \mathrm{r}$, held a meeting at the same time as the International Meteorological Committee, and presented a report dealing with definitions for the ten classes (Hildebrandsson and Abercromby) adopted at Munich, and with instructions for cloud observations. They also proposed to prepare and issue an authoritative cloud atlas. This report was carefully discussed and, after modification, adopted. The members of the Cloud Committee who were present at the meeting, were Prof. Hildebrandsson, Dr. Hann, Prof. Mohn, Mr. A. L. Rotch (Bliue Hill Observatory), M. Teisserenc de Bort. In addition, the following gentlemen were admitted, but without voting power: Prof, v. Bezold, Dr. Billwiller, and Mr. Davis (of the International Meteorological Committee), and Prof. Broounof (Kieff), Dr. Fineman and Dr. Hagström (Upsala), Prof. Riggenbach (Basle), Prof. Sprung (Potsdam), and M. Philip Weilbach (Copenhagenj. (6) The subject of the treatment of the wet bulb below the freezing point was discussed, and the use of Ekholm's formula was recommended ad interin. (7) It was decided to arrange for a conference of the same character as that at Munich in 1891 , which was not an official congress, to be held in Paris in September 1896. M. Mascart and Mr. Scott were requested to make the necessary preparations, such as the arrangement of the programme, \&c.

THE great pine forest region in the States of Minnesota and Wisconsin has been devastated by fire. There had been no rain in the district for nine weeks, and the trees had there. fore become very dry and inflammable. Forest fires occurred in the early part of last week, but their advance was checked. On Friday, however, several fires broke out almost simultaneously, and the flames spread with alarming rapidity. Many towns and villages were entirely destroyed, and it is estimated that nearly one thousand lives were lost.

A RECENT number of the official organ of the National Department of Hygiene in Buenos Ayres, a copy of which has been sent to us, calls attention to a hygienic exhibition which is to be held in that city at the close of this month. The authorities hope that it may render important service in helping to establish a permanent museum of practical hygiene, besides stimulating public interest in sanitary questions generally. The journal also contains many useful notices of original work published in various foreign papers.

THe current numbers of the British Medical fournal and the Lancet should be obtained by everyone desirous of entering the medical profession. They are almost entirely devoted to descriptions of the universities, corporations, and colleges which grant the degrees and diplomas required by a medical practitioner. Prospective students will find our contemporaries complete guides to the medical calling. They will also find that to succeed in this noble profession it is necessary that a man " should be imbued with a love of humanity and a love of science, and should be indifferent to the worship of the god of the modern world-the golden calf. No man whose aim is to make a fortune should dream of entering the medical profession. Let him learn the grocery business or the drapery business ; he will not only fail in medicine, but will help to degrade it." These remarks are applicable to students of most branches of science.

Some years ago, an observatory was established on the SaintJacques tower in Paris, under the direction of M. J. Jaubert. The institution is of a private nature, but it is furnished with 